\title{
Pump-induced platelet aggregation with subsequent hypotension: Its mechanism and prevention with clopidogrel
}

Piet Borgdorff, PhD, and Geert Jan Tangelder, MD, PhD

Supplemental material is available online.
From the Institute for Cardiovascular Research, Vrije Universiteit Medical Center, Amsterdam, The Netherlands.

Received for publication Aug 16, 2005; revisions received Oct 10, 2005; accepted for publication Oct 11, 2005.

Address for reprints: P. Borgdorff, PhD, Laboratory for Physiology, VUMC, Van der Boechorststraat 7, 1081 BT Amsterdam, The Netherlands (E-mail: p.borgdorff@ vumc.nl).

J Thorac Cardiovasc Surg 2006;131:813-21

$0022-5223 / \$ 32.00$

Copyright $@ 2006$ by The American Association for Thoracic Surgery

doi:10.1016/j.jtcvs.2005.10.021
Objectives: Use of extracorporeal circuits in cardiopulmonary bypass and hemodialysis often causes bleeding problems and hypotension. As shown previously, this might be caused by activation of blood platelets due to pumping. The present study investigates the mechanism of pump-induced platelet aggregation and its possible prevention.

Methods and Results: Continuous measurement of platelet aggregation in an extracorporeal shunt from a carotid to a femoral artery in rats showed that aggregation during the first 10 minutes of pumping was not reduced by coating the tube with albumin or heparin nor by using dalteparin instead of unfractionated heparin as anticoagulant. Also, pump characteristics seemed unimportant because aggregation could already be elicited by single tube compression with one pump roller. It was calculated that during compression wall shear stress in the tube rises far beyond the values known to induce platelet aggregation, occurring also in clinically used roller pumps. A crucial role for adenosine diphosphate was demonstrated by blockade of platelet adenosine diphosphate- $\mathrm{P} 2 \mathrm{Y}_{12}$ receptors with the clinically used drug clopidogrel $(50 \mathrm{mg} / \mathrm{kg}$ intravenously, $\mathrm{n}=8)$. This prevented platelet aggregation and the fall of systemic blood pressure (to $71 \% \pm 12 \%$ in controls, $n=6$ ) during 2 hours of continuous pumping.

Conclusion: We conclude that pump-induced platelet aggregation is not caused by factors released from the tube or its coating but is initiated by short bouts of high shear stress, and its continuation is critically dependent on adenosine diphosphate. The latter might have clinical relevance for patients connected to extracorporeal systems.

$\mathrm{U}$ se of extracorporeal systems in cardiopulmonary bypass and hemodialysis often causes severe hypotension and excessive bleeding. ${ }^{1,2}$ Our work with human and rat blood suggests that these problems may be largely caused by platelet activation in the tubing of the pumps used. ${ }^{3,4}$ Autoperfusion did not affect platelets or hemodynamics in an extracorporeal shunt from a carotid to a femoral artery of rats, but insertion of a roller pump immediately elicited strong platelet aggregation, serotonin (5-HT) release, and systemic hypotension. Hypotension could be prevented with blockade of $5-\mathrm{HT}_{2}$ receptors or by inhibition of nitric oxide (NO) production, suggesting that the aortic pressure decrease resulted from endothelial $\mathrm{NO}$, the release of which was triggered by serotonin from activated platelets. ${ }^{5}$ $5-\mathrm{HT}_{2}$-receptor blockade did not affect the intensity of aggregation, indicating that 5-HT had cardiovascular effects only and was not critically involved in the process of platelet aggregation.

The mechanism of pump-induced platelet aggregation has not been fully clarified. Activation of platelets in our setup was not due to hemolysis, ${ }^{3}$ blood-air contact, or cessation of flow in reservoirs. Platelets, however, might be stimulated by factors released from the pump tubing or its coating or by high shear stress. 


\author{
Abbreviations and Acronyms \\ ADP = adenosine diphosphate \\ $\mathrm{CPB}=$ cardiopulmonary bypass surgery \\ EDTA $=$ ethylenediamine tetraacetic acid \\ 5 -HT $=$ serotonin \\ $\mathrm{NO}=$ nitric oxide \\ $\mathrm{SD}=$ standard deviation \\ SEM $=$ standard error of the mean \\ vWf $=$ von Willebrand factor
}

Initiation of platelet activation by shear stress is suggested by the absence of pump-induced platelet aggregation after administration of aurintricarboxylic acid, ${ }^{4}$ which inhibits binding of a shear stress-exposed A1 domain of plasma von Willebrand factor (vWf) to platelet glycoprotein Ib receptors. ${ }^{6,7}$ The present study therefore compared the pump effect in tubes coated with albumin or heparin to that in uncoated tubes or tubes devoid of plasticizers. We also estimated the time-varying magnitude of the shear stresses in the pump tubing with the aid of a mathematical model; we also investigated the contribution of adenosine diphosphate (ADP) by blocking platelet $\mathrm{ADP}-\mathrm{P} 2 \mathrm{Y}_{12}$ receptors with the clinically approved drug clopidogrel.

\section{Methods}

The experimental setup has been described in detail previously. ${ }^{5}$ In short, Wistar rats (330-450 g) were anesthetized with ketamine $(60 \mathrm{mg} / \mathrm{kg}$ intramuscularly) and pentobarbital (35 mg/kg intraperitoneally, followed by $10-14 \mathrm{mg} / \mathrm{kg}$ per hour intravenously), ventilated, and anticoagulated with unfractionated heparin (Leo Pharmaceutical Products BV, Weesp, The Netherlands, 800 IU/kg). In rats this dose is required when they are connected to an extracorporeal system. In one set of experiments animals were anticoagulated with low-molecular-weight heparin (Dalteparin, Kabi, Stockholm, Sweden, $600 \mathrm{IU} / \mathrm{kg}$ ). Body temperature was kept at $37.5^{\circ} \mathrm{C}$. All animal handling was in compliance with the Guide for the Care and Use of Laboratory Animals (NIH publication no. 85-23, revised 1985).

An extracorporeal shunt tube was placed between the proximal part of a carotid and distal part of a femoral artery and loosely positioned in a roller pump with 8 rollers (see Appendix). Initial spontaneous flow from carotid to femoral artery, measured with an inline flow probe (1N, Transonic Systems Inc, Ithaca, NY), was converted to pump perfusion by tightening the rollers with a calibrated screw just until flow stopped and by starting the pump at a speed that restored flow to its original level. The calibration on the screw allowed position of the rollers to be identical in all experiments. Aortic and femoral pressures were measured via stainless steel T-pieces in the shunt at $\sim 30 \mathrm{~mm}$ from the cannulas. To use the vascular bed of the leg as "bioassay," we continuously measured femoral resistance as the ratio of mean femoral artery pressure over flow.

Platelet aggregation downstream of the pump was continuously measured with a photometric device, which detects an increase in light transmission when platelet aggregates pass through a glass capillary. ${ }^{8}$ For quantitation the signals were converted to uniform spikes and counted over 10-second periods. For comparison of platelet count and volume before and after 2 hours of pump perfusion a Helios blood cell counter (ABX Diagnostics, Montpellier, France) was used.

In a first series of experiments we compared the intensity of pump-induced platelet aggregation in 3 different circuits: uncoated, coated with Duraflow-II heparin by Edwards Lifesciences, or coated with albumin. ${ }^{9}$ In all subsequent experiments we used albumin-coating to minimize the effects of blood-material contact. Albumin is as effective in this respect as heparin coating ${ }^{10,11}$ and has the additional advantage that possible direct effects of surfacebound heparin on platelets are avoided.

Clopidogrel, a potent platelet ADP-P2 $\mathrm{Y}_{12}$-receptor antagonist (Sanofi-Synthelabo, Toulouse, France) was dissolved in saline and administered intravenously $(50 \mathrm{mg} / \mathrm{kg})$. To be effective, this thienopyridine compound was allowed to be metabolized in the liver for at least 30 minutes $^{12}$ before experiments started.

Stability of the platelet aggregates was studied in vitro with a modification of the "Wu and Hoak-method"13: blood samples were divided in 2 parts of $0.1 \mathrm{~mL}$, which were added to ethylenediamine tetraacetic acid (EDTA) solutions $(0.4 \mathrm{~mL})$ with different final concentrations. A concentration of $5 \mathrm{mmol} / \mathrm{L}$ EDTA was used to prevent further aggregation, and a concentration of $10 \mathrm{mmol} / \mathrm{L}$ EDTA was used to dissolve reversible aggregates. Within 30 minutes after blood collection a hemolysing agent (Thromboplus, Sarstedt, Nümbrecht, Germany) was added and platelets and aggregates (larger than two clumped platelets) were counted with help of a Bürker counting chamber using brightfield microscopy. The reliability of the method was verified on blood in which both stable and unstable aggregates were produced by adenosine 3,5diphosphate (ADP), in a final concentration of $40 \mu \mathrm{mol} / \mathrm{L}$. Photographs of the samples were made on a 3I Marianas inverted microscopy workstation (Denver, CO) using its differential interference contrast imaging modality.

The effect of a few or only a single tube occlusion on platelet aggregation, without interrupting blood flow to the hind leg, was studied with aid of the same pump after removing 6 of the 8 rollers. This made it possible to perform these compressions with the same rotation speed and occlusiveness of the roller, as in the experiments with all rollers in place. In contrast to the situation with 8 rollers, autoperfusion is not taken over by the pump when 6 of 8 rollers are missing.

We employed a mathematical model, based on the NavierStokes equations, for estimation of time-varying wall shear stress values in the tubings of our experimental pump and a clinical hemodialysis pump; this model is an extension of a model previously used to estimate shear stress under static flow conditions. ${ }^{8}$ The model is presented in Appendix E1.

\section{Statistics}

Values in text, legends, and table are expressed as mean \pm standard deviation (SD); values in the figures as mean \pm standard error of the mean (SEM). For comparison of platelet counts and volume before and after pump perfusion (Table 1) the paired $t$ test was 
A

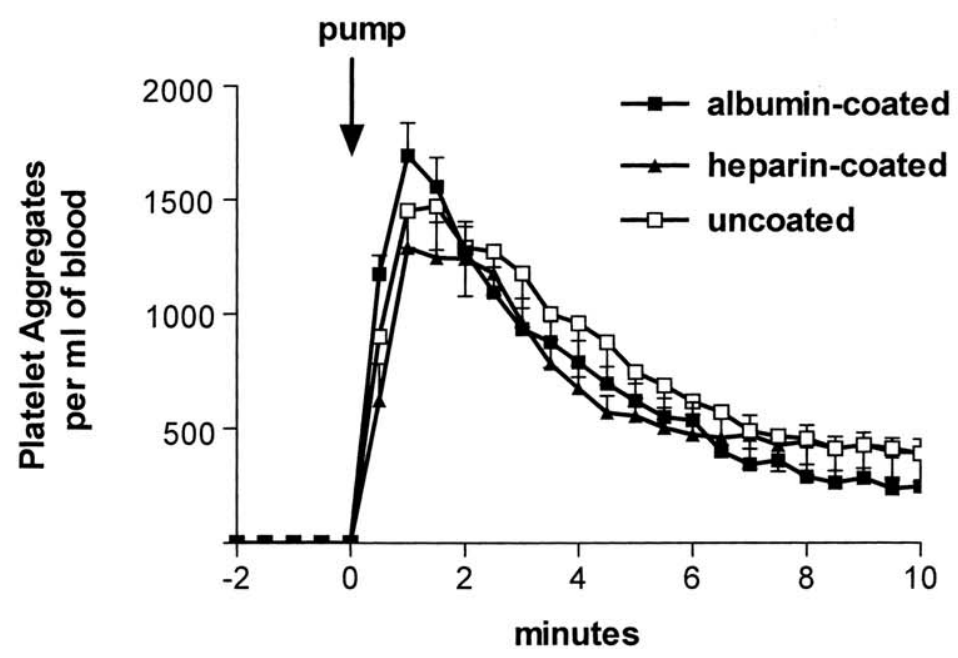

B

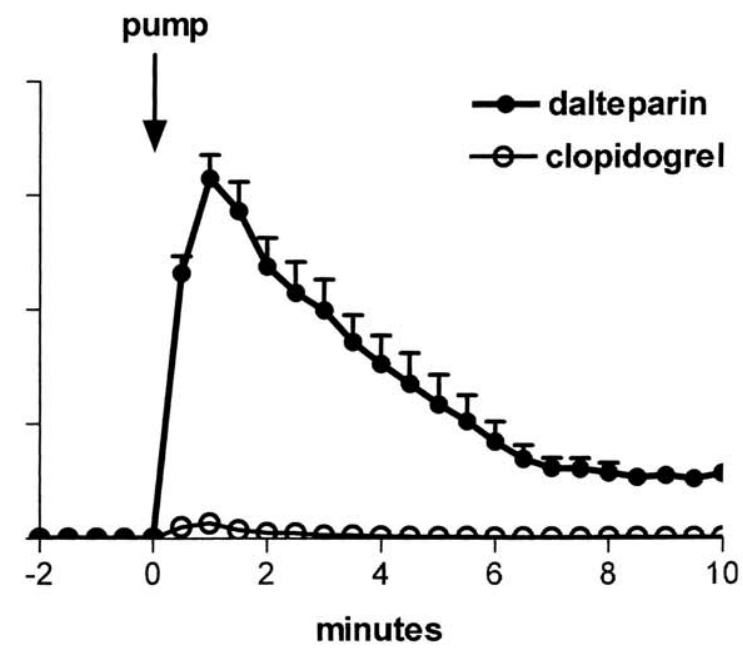

Figure 1. A, Amount of platelet aggregation during the first 10 minutes of pump perfusion is $\operatorname{similar}(P=.53)$ for albumin-coated tubes $(n=6)$ and heparin-coated tubes $(n=6)$, as well as for uncoated $(n=6)$ tubes in animals anticoagulated with unfractionated heparin. Note the absence of aggregation before pump start $(t=0)$. B, Platelet aggregation is also elicited in albumin-coated tubes when dalteparin $(n=7)$ is used as anticoagulant but is virtually absent after ADP-P2Y ${ }_{12}$-receptor blockade with clopidogrel (n $=8, P<.0001$ ).

used. Time series data under different conditions (Figure 1) were analyzed with 2-way analysis of variance for repeated measurements.

\section{Results}

Pump-Induced Platelet Aggregation Does Not Depend on Tube Characteristics or Choice of Anticoagulant Although autoperfusion did not affect platelets or hemodynamics, start of the pump immediately elicited strong platelet aggregation, which was maximal within the first 3 to 5 minutes. It then leveled off but remained present for the next 2 hours of pumping. Figure 1, A illustrates that the amount of platelet aggregation in heparinized animals during the first 10 minutes after pump start was not significantly different whether the system was coated with albumin or with heparin or not coated at all. This illustrates that aggregation does not result from albumin or heparin released from the coating during squeezing of the tube. Neither is the aggregation initiated by release of plasticizers from the tubing, because experiments with silicone or polyurethane tubing, which are devoid of plasticizers, yielded similar results (not shown).

Also, anticoagulation with dalteparin instead of unfractionated heparin did not diminish platelet aggregation (Figure 1, B), indicating that the pump-induced platelet aggregation did not depend on a specific influence of unfractionated heparin on platelet behavior.
Platelet Aggregation Can Even Be Evoked by a Single Roller Compression

To study whether aggregation of platelets during pump perfusion was an effect of the high frequency of tube compressions in the pump used, we reduced this frequency from 120/min to 30/min by removing 6 of 8 rollers from the pump $(\mathrm{n}=5)$. Also with this lower compression frequency, but with the same roller speed as used in the experiments with 8 rollers, strong platelet aggregation was observed (Figure 2, left panel). Aggregation could also be elicited by a small series of separate compressions, and, interestingly, even by a single compression (Figure 2, middle and right panel, respectively). Despite the short duration of a single compression, aggregation continued for $28 \pm 3.8$ seconds $(\mathrm{n}=19)$ at $15 \mathrm{~cm}$ after the pump. Elongation of the tube between pump and aggregometer revealed that the duration of aggregation increased with distance, to $143 \pm 16(\mathrm{n}=7)$ seconds at $75 \mathrm{~cm}$. This indicates that aggregation inside the tube was self-reinforcing.

Experiments with lengthened tubes also demonstrated that the propagation speed of the aggregates was only half of mean blood velocity in the first $15 \mathrm{~cm}$; the propagation speed then increased and exceeded mean blood velocity after about $55 \mathrm{~cm}$. This indicates that the aggregates move close to the tube wall within the first $15 \mathrm{~cm}$ and more centrally further on. 


\title{
Aggregation
}
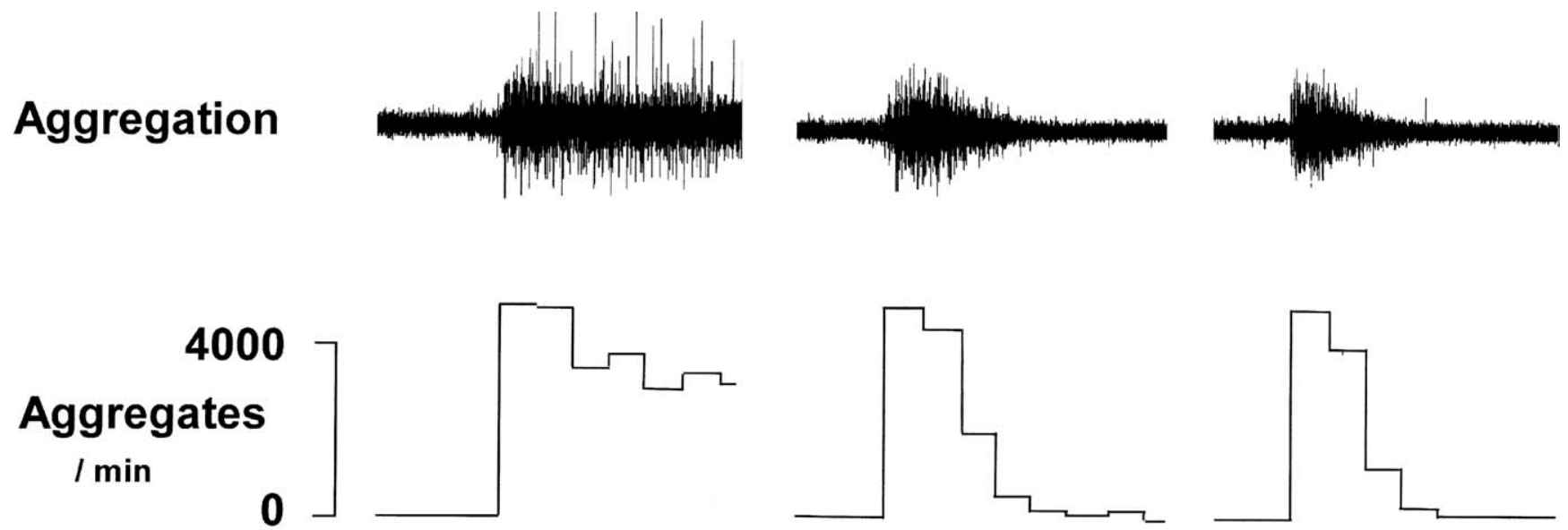

Flow

$\mathrm{ml} / \mathrm{min}$
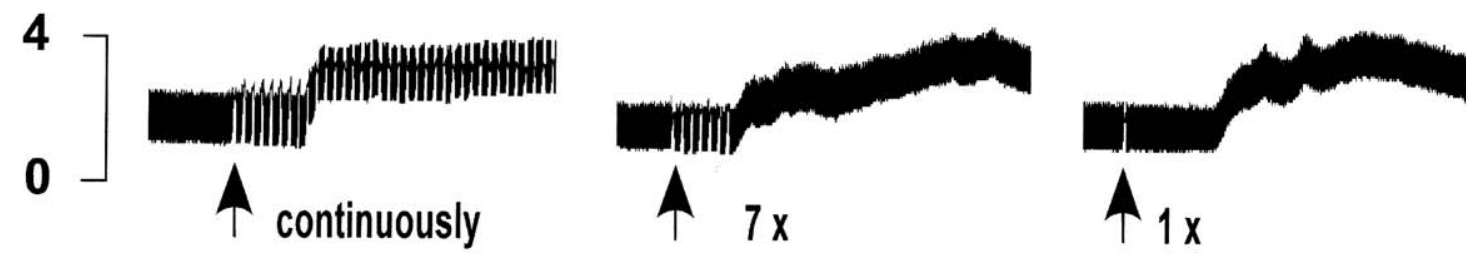

Time
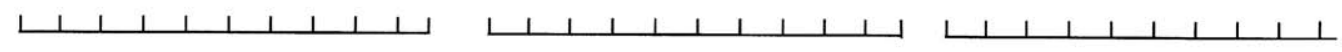

\section{(10 $s$ periods)}

\begin{abstract}
Figure 2. Recordings of platelet aggregation elicited during autoperfusion by continuous repetitive (left panel) and by 7 (middle panel) and by a single (right panel) tube compression (visible in the flow tracing). Even a single compression and decompression, together lasting about $100 \mathrm{~ms}$, is sufficient to elicit platelet aggregation for about 25 seconds (right panel). Upper tracing, Raw signal; middle tracing, quantification over 10-second periods. Note the resulting increase of flow to the hind leg. In these experiments flow was not fixed because the adapted pump had no driving effect on flow.
\end{abstract}

Figure 2 additionally shows that blood flow to the hind leg during platelet aggregation in these experiments increased, and thus did not show the triphasic response (vasodilation-vasoconstriction-vasodilation) seen during regular pumping (ie, when aggregation is more intense and more serotonin will be released). The vascular reaction to serotonin depends on its concentration. ${ }^{5}$

Shear Stress Values during a Single Tube Compression in a Roller Pump

Figure 3 presents shear stress values at the tube wall as a function of time or tube slit height for 2 different roller pumps. When the slit height in the pump tubing becomes smaller than about $20 \mu \mathrm{m}$ (see upper axis in Figure 3), the shear stress values far exceed the level of about 120 dynes/ $\mathrm{cm}^{2}$ reported to elicit platelet aggregation. ${ }^{7}$ The corresponding time periods during every compression or decompres- sion of the tube are $25 \mathrm{~ms}$ in our small laboratory pump (A) and $17 \mathrm{~ms}$ in a clinical pump (B).

Crucial Role for ADP: Prevention with Clopidogrel Blockade of platelet ADP-P2 $\mathrm{Y}_{12}$ receptors with clopidogrel in animals that were anticoagulated with unfractionated heparin nearly completely prevented aggregation (Figure 1, B). Also the 2-phasic fall in aortic pressure, in controls to $81 \% \pm 12 \%$ (mean $\pm \mathrm{SD}$ ) during the first 5 to 10 minutes and to $71 \% \pm 12 \%$ at 2 hours of pumping, remained absent (Figure 4, A). Because the drops in aortic pressure are known to be elicited by platelet-released serotonin, ${ }^{5}$ their absence indicates that clopidogrel not only prevents platelet aggregation but also impairs the release of serotonin.

Figure 4, B shows the effect of clopidogrel on the reaction of femoral resistance. Although in controls femoral resistance showed a triphasic pattern after pump start (a short 


\section{Slit height under roller $(\mu \mathrm{m})$}

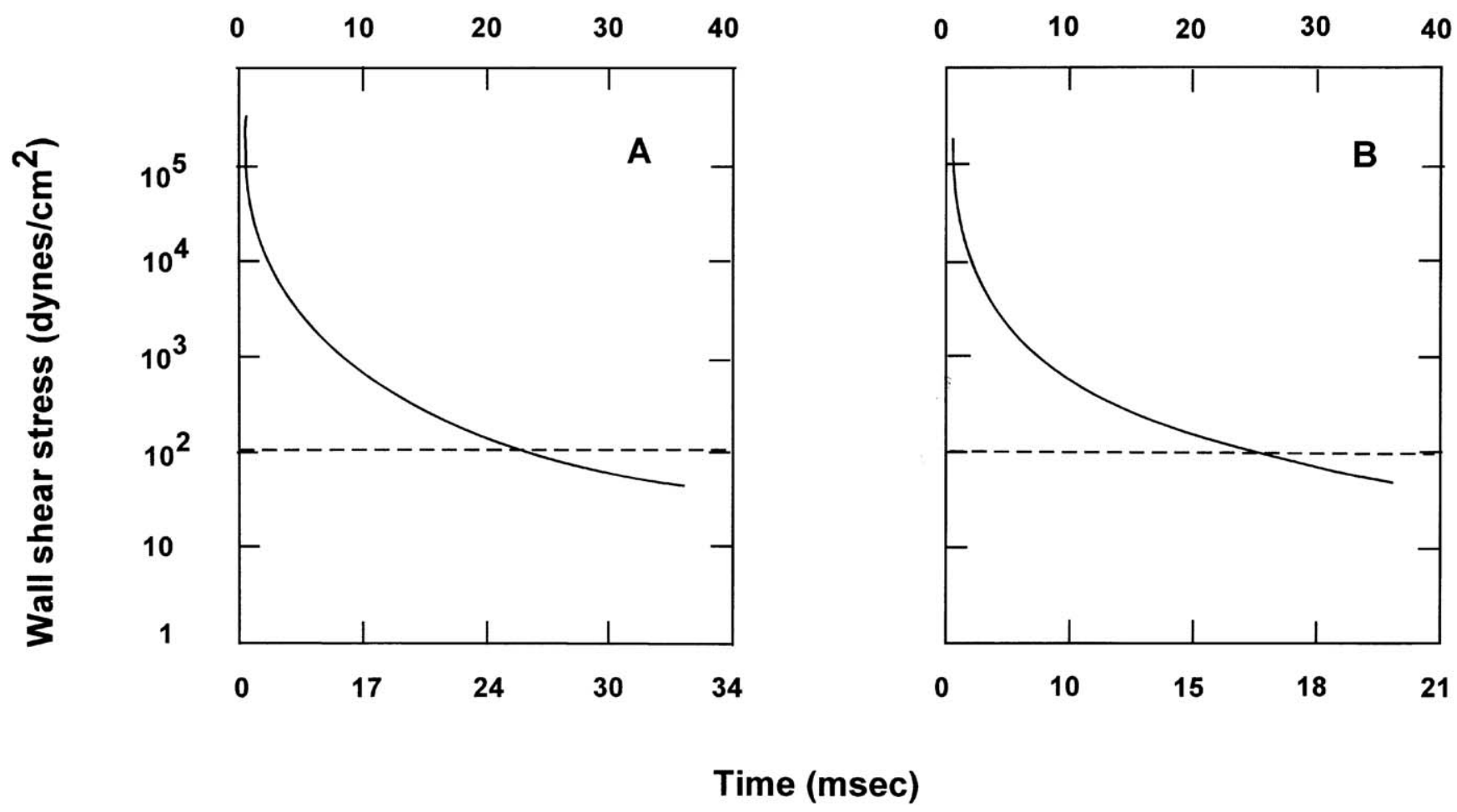

Figure 3. Wall shear stresses in the tubing of the small pump used for the present study (A, 8 rollers) and in an AK 10 Gambro hemodialysis pump (B, 2 rollers). Flow was set to be $3 \%$ to $5 \%$ of cardiac output $(3$ and $225 \mathrm{~mL} / \mathrm{min}$, respectively). The lower horizontal axis depicts the time before or after complete occlusion; the upper horizontal axis indicates the slit height under a roller. The dotted line represents the level above which aggregation can be expected. Rotation rate of both pumps: 20 revolutions/min. For further details see appendix.

decrease, a rise of $5-10$ minutes to $141 \% \pm 13 \%$, and a long-lasting fall to $64 \% \pm 14 \%$ ), it only decreased in the presence of clopidogrel.

\section{Aggregate Lability and Prevention of Platelet \\ Loss by Clopidogrel}

Microscopic inspection of blood samples from the return line in control experiments showed only single platelets before pump start (see Figure 5, A) but revealed many aggregates $\left(33 \pm 21 \times 10^{9} / \mathrm{L}, \mathrm{n}=5\right)$ and a decrease in free platelet number of $42 \% \pm 15 \%$ after 1 minute of pumping. The aggregates varied in size from duplets to platelet clumps with a diameter of more than $100 \mu \mathrm{m}$ (for examples see Figure 5, B and C). However, as shown in Figure 5, D, these aggregates were not stabilized and could easily disintegrate, yielding a free platelet count similar to control $(103 \% \pm 10 \%)$. Though being labile, the aggregates did not fall apart in the tubing, as seen when the tube between pump and aggregometer was elongated from 15 to $75 \mathrm{~cm}(\mathrm{n}=7)$. Because blood did not contain aggregates when it had passed the body (ie, at the entrance of the extracorporeal circuit), platelets most likely desegregated in the microcirculation of hind leg and lungs.

The lability of the aggregates also appeared from platelet counts. After 2 hours of pumping, platelet loss in our control experiments was only $14 \%$ (from $844 \pm 59$ to $695 \pm 9110^{9} / \mathrm{L}$; means $\pm \mathrm{SD}, \mathrm{n}=7, P=.0005)$, which is far less than the $42 \%$ decrease seen within the first minute after pump start (see above). The number of platelets did not significantly decrease after pretreatment with clopidogrel $(884 \pm 59$ to $874 \pm 67$ $\left.10^{9} / \mathrm{L}, \mathrm{n}=8, P=.25\right)$, that is, in the absence of aggregation. Clopidogrel also prevented the reduction in platelet volume, which in control experiments amounted $3.2 \%$ (from $5.2 \pm 0.27$ to $5.0 \pm 0.21 \mathrm{fL} ; P=.0005)$ and which indicates that the platelets, despite their disaggregation, did not fully recover.

\section{Discussion}

The present study shows that pump-induced platelet aggregation occurs both with unfractionated heparin and with 
A
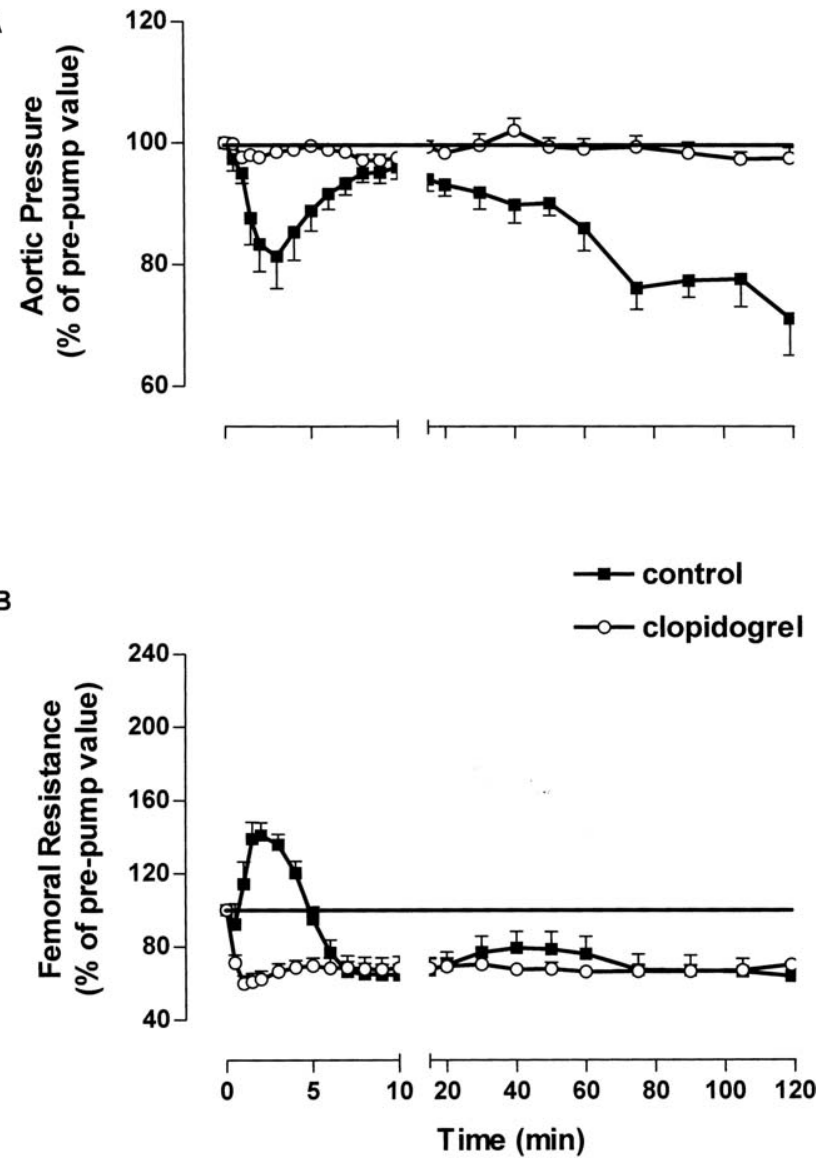

Figure 4. Aortic pressure (A) and femoral resistance (B) after onset of pump perfusion ( $t=0$; mean \pm SEM). Clopidogrel prevented both the first and second hypotensive reaction as well as the rise in femoral resistance $(P<.001)$. It had no influence on the long-lasting femoral vasodilation $(P=.71)$. Initial aortic pressures (mean \pm SD at time 0 ) were $137 \pm 15$ (control, $n=6$ ) and $114 \pm 10 \mathrm{~mm} \mathrm{Hg}$ (clopidogrel, $\mathrm{n}=8$ ); the respective initial femoral resistances were $58 \pm 17$ and $60 \pm 12 \mathrm{~mm} \mathrm{Hg} \cdot \min \cdot \mathrm{mL}^{-1}$.

dalteparin anticoagulation and does not depend on the presence or type of coating or on plasticizers in the tubing. Therefore, pump-induced platelet activation seems, in the absence of subendothelial collagen and with negligible hemolysis, ${ }^{3}$ to not be initiated by agonists released from the tubing but by a physical stimulus, for example, shear stress. Aggregation could be elicited even by a single tube compression and continued in the tubing behind the pump, although the aggregates were unstable. The platelets probably desegregated during passage through the microcirculation of the perfused leg because femoral resistance showed, after an increase for some minutes, a long-lasting decrease, and no aggregates were observed in the blood that left the body. It was calculated that compression and decompression of the tube produced shear stresses that far exceeded the values reported necessary for platelet aggregation. We also demonstrated a crucial role for ADP by preventing both platelet aggregation and the subsequent hypotension with clopidogrel.

Accordingly, the proposed sequence of events leading to pump-induced platelet aggregation is highlighted in Figure 6. In high shear stress fields platelets are deformed and large plasma multimers of vWf undergo a conformational change from a globular state into an extended chain, thereby presenting their A1 domain that binds to platelet glycoprotein Ib receptors. ${ }^{14,15}$ This starts platelet activation by mobilization of calcium, ${ }^{16}$ which, among other factors, leads to release of ADP and serotonin from dense granules and of $\mathrm{vWf}$ from alpha granules. ${ }^{7}$ ADP stimulates purinergic P2 ${ }_{12}$ receptors on the membrane of the same and other platelets, promoting aggregation by activation of platelet GPIIB/IIIA receptors that bind fibrinogen as well as the adhesive plasma- and platelet-released vWf., ${ }^{6,17}$ At high shear stresses (above 100 dynes $/ \mathrm{cm}^{2}$ ) platelet aggregation becomes aspirin-insensitive, ${ }^{19,20}$ probably because mainly the release of vWf from platelet alpha granules is stimulated, which is not inhibited by aspirin. ${ }^{21}$

The initiating role of shear stress in pump-induced platelet aggregation is corroborated by the absence of aggregation, when the vWf-GP1b receptor binding is blocked with aurintricarboxylic acid or a recombinant $\mathrm{vWf}$ fragment, ${ }^{3}$ and by its low sensitivity to aspirin treatment (submitted). Furthermore, aggregate formation could be successfully prevented by selective blockade of platelet ADP-P2 $\mathrm{Y}_{12}$ receptors with clopidogrel. A similar pivotal role of ADP has been demonstrated for shear-induced platelet aggregation in vitro. ${ }^{17,22}$ Serotonin, which like ADP is also released from dense granules, does not contribute to the aggregation under these circumstances but has mainly cardiovascular effects ${ }^{5}$ (Figure 6).

Clopidogrel did not prevent vasodilation in the femoral bed of our rats (see Figure 4). This vasodilation may have been caused by small amounts of serotonin ${ }^{5}$ and/or by ADP released from activated but nonaggregating platelets. ADP causes vasodilation via clopidogrel-insensitive $\mathrm{P}_{2} \mathrm{Y}_{1}$ receptors in the vascular wall. ${ }^{23}$

The residence time of platelets in the shear field of the pump tubing is several orders of magnitude shorter than the 30 seconds or more required for shear-induced platelet aggregation in vitro. ${ }^{24}$ It is compatible, however, with the short residence time $(49 \mathrm{~ms})$ in an in vivo study where we partially compressed a shunt tube with a small static occluder, ${ }^{8}$ creating a fixed shear stress of 231 dynes $/ \mathrm{cm}^{2}$. Shear stress-induced platelet aggregation with short residence times seems more in line with the clinical situation in which thrombosis results from aggregation of platelets that pass the high shear field of an arterial stenosis or obstructed stent. ${ }^{19,25}$ The lower sensitivity of platelets for very short periods of shear stress in vitro might be caused by the use of 

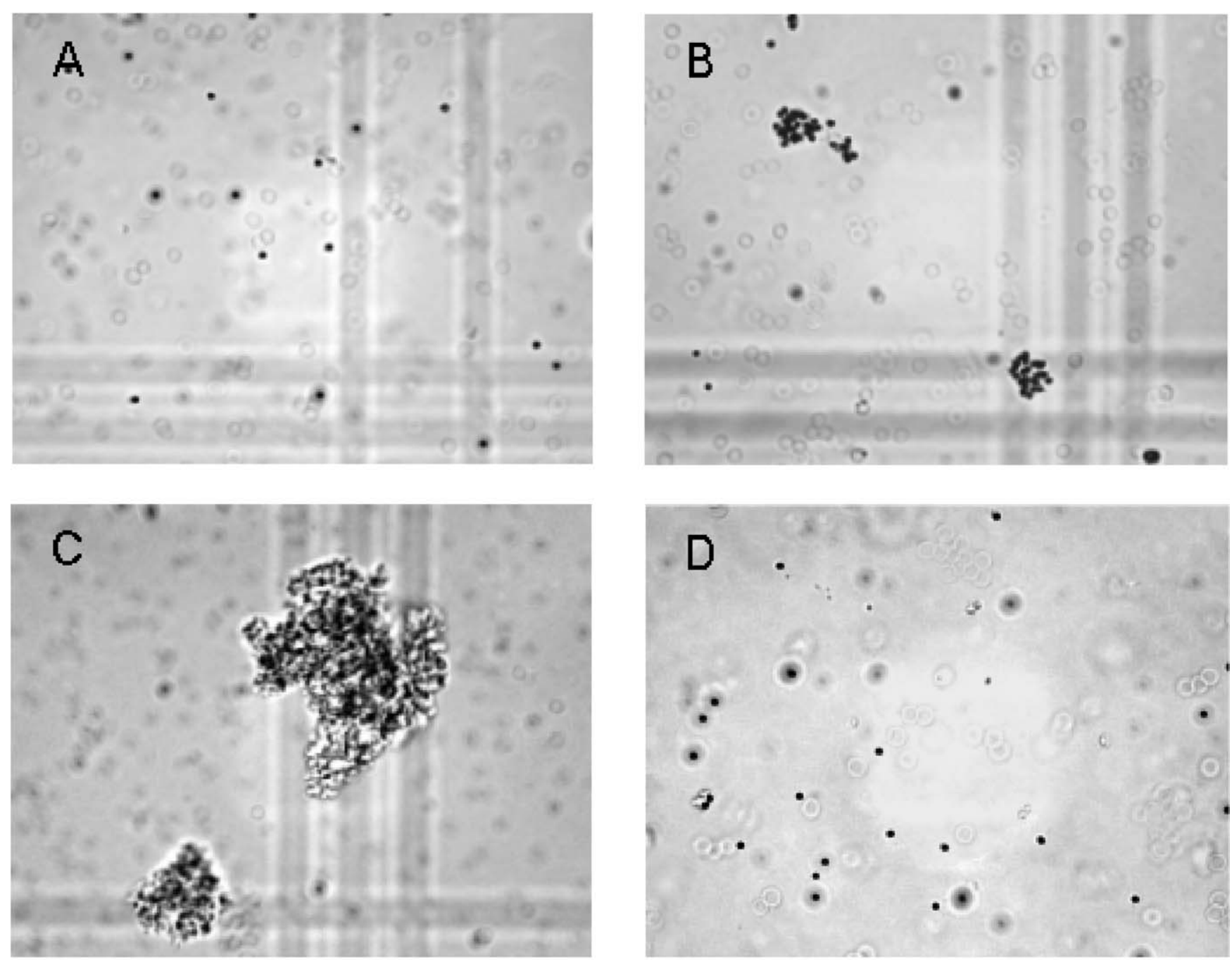

\section{$50 \mu \mathrm{m}$}

Figure 5. During pumping many, sometimes even very large, aggregates are formed (B and $C$ ) that disintegrate (D) under the influence of $10 \mathrm{mmol} / \mathrm{L}$ EDTA. A, Before pumping. Individual platelets (small black dots) and aggregates were microscopically inspected in a Bürker counting chamber.

citrate as anticoagulant because pump perfusion does not induce platelet aggregation when the blood has been anticoagulated with citrate instead of heparin. ${ }^{4}$

The experiments with single roller compression revealed a remarkable phenomenon: about $50 \mathrm{~ms}$ of high shear stress were sufficient to elicit platelet aggregation for at least 28 seconds when measured at $15 \mathrm{~cm}$ distance from the pump and for even 143 seconds when measured at $75 \mathrm{~cm}$ distance. An explanation for this ongoing aggregation is suggested by measurements of aggregate velocity. This velocity was initially lower than mean blood velocity, indicating that the aggregates moved close to the tube wall. Close contact with the tube wall could have been mediated by vWf, which is known to adhere even to coated material. ${ }^{14,26,27}$ The low initial velocity of the aggregates might enable them to also activate other, unstimulated platelets that pass by more centrally.

\section{Clinical Interest}

Magnitude and duration of calculated shear stresses during pumping were of the same order in a clinically used roller pump and in our small pump (see Figure 5), suggesting that the dimensional characteristics of the pump are not decisive. Moreover, aggregation could also be evoked (though less intensively) by nonocclusive compression and by compress- 


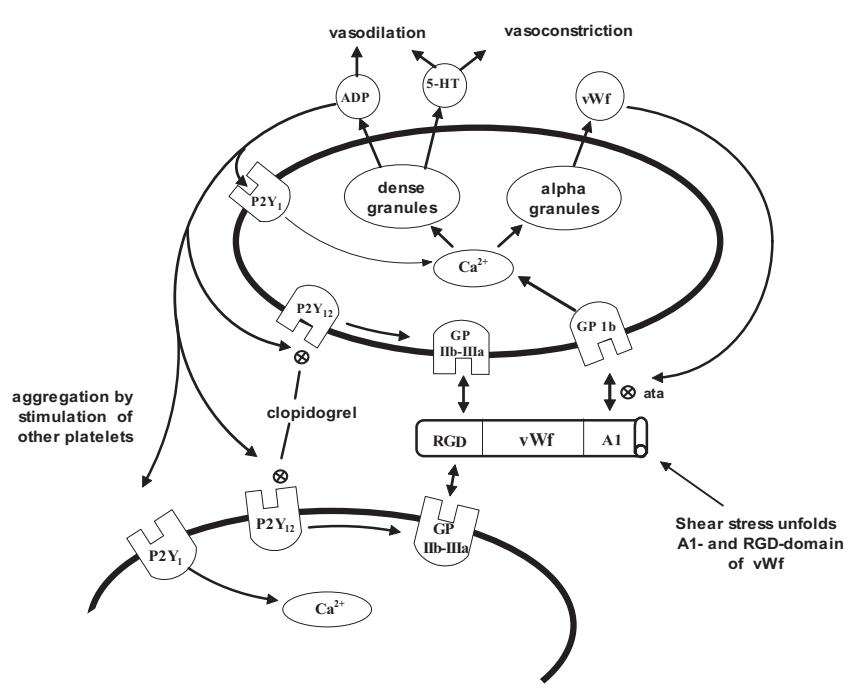

Figure 6. Supposed mechanism of pump-induced platelet aggregation, based on results of the present and previous studies ${ }^{3,5}$ and on literature about shear stress-induced platelet aggregation. Shear stress causes a conformational change of plasma vWf and possibly a deformation of platelets. Binding of the exposed vWf A1 domain to platelet GPIb receptors triggers intracellular calcium $\left(\mathrm{Ca}^{2+}\right)$ mobilization with subsequent release of ADP and 5-HT from dense granules and of vWf from alpha granules. Although 5-HT mainly has cardiovascular effects, ADP stimulates $P 2 Y_{12}$ receptors on the same and other platelets to activate GPIIB/IIIA receptors that bind fibrinogen and vWf, which causes aggregation. The cascade of events can be interrupted ( $(\otimes)$ by aurintricarboxylic acid (ata) and by clopidogrel.

ing the tube with the fingers (not shown). Also, the material of the tubing or the presence of coating did not matter. The present results therefore strongly suggest that a similar shear stress-induced platelet aggregation will be evoked by other roller pumps used in hemodialysis, cardiopulmonary bypass surgery (CPB), and extracorporeal membrane oxygenation, and also in centrifugal pumps in which shear stress may reach values between 400 and 2730 dynes $/ \mathrm{cm}^{2} .^{28}$

In our experimental setup these pump effects could be prevented with clopidogrel. In cardiovascular surgery, however, clopidogrel has been reported to cause excessive bleeding, ${ }^{29}$ especially when combined with use of aspirin. ${ }^{30}$ Therefore, in the clinic ADP antagonists with a much shorter half-life than clopidogrel might be required. Alternatively, pump-induced platelet aggregation might be prevented, as can deduced from Figure 6, by reversible inhibition of platelet GPIIb/IIIa or GPIb receptor activity, ${ }^{31} \mathrm{vWf-GPIb}$ receptor binding, or by making the blood calcium-free during its passage through the circuit, as in citrate hemodialysis. ${ }^{32}$

It remains to be determined how much pump-induced platelet aggregation contributes to post-CPB complications compared to the important effects of other factors like blood-air contact and retransfusion of cardiotomy blood with subsequent generation of thrombin. ${ }^{33}$ We conclude that use of a roller pump in extracorporeal circuits generates short bouts of high shear stress that initiate ADP-dependent platelet aggregation and hypotension, which can be prevented by blocking ADP-P2 $Y_{12}$ receptors with clopidogrel. These effects could partially explain the complications seen in clinical extracorporeal circulation.

We thank Dr. M.A. Vis for developing a mathematical model to estimate shear stress in the pump tubing and Dr. R. Musters for preparing the photographic pictures of platelets and their aggregates in a Bürker counting chamber.

\section{References}

1. Reich DL, Bodian CA, Krol M, Kuroda M, Osinski T, Thys DM. Intraoperative hemodynamic predictors of mortality, stroke, and myocardial infarction after coronary artery bypass surgery. Anesth Analg. 1999;89:814-22.

2. Zucchelli P, Santoro A. Dialysis-induced hypotension: a fresh look at pathophysiology. Blood Purif. 1993;11:85-98.

3. Borgdorff P, van den Bos GC, Tangelder GJ. Extracorporeal circulation can induce hypotension by both blood-material contact and pump-induced platelet aggregation. J Thorac Cardiovasc Surg. 2000;120:12-19.

4. Borgdorff P, van Den Berg RH, Vis MA, van den Bos GC, Tangelder GJ. Pump-induced platelet aggregation in albumin-coated extracorporeal systems. J Thorac Cardiovasc Surg. 1999;118:946-52.

5. Borgdorff P, Fekkes D, Tangelder GJ. Hypotension caused by extracorporeal circulation: serotonin from pump-activated platelets triggers nitric oxide release. Circulation. 2002;106:2588-93.

6. Alevriadou BR, Moake JL, Turner NA, Ruggeri ZM, Folie BJ, Phillips, MD et al. Real-time analysis of shear-dependent thrombus formation and its blockade by inhibitors of von Willebrand factor binding to platelets. Blood. 1993;81(5):1263-76.

7. Moake JL, Turner NA, Stathopoulos NA, Nolasco L, Hellums JD. Shear-induced platelet aggregation can be mediated by vWF released from platelets, as well as by exogenous large or unusually large vWF multimers, requires adenosine diphosphate, and is resistant to aspirin. Blood. 1988;71:1366-74.

8. Borgdorff P, Kok WE, Vis MA, van den Bos GC. Vasodilation by shear-induced platelet aggregation in extracorporeal circuits. Am J Physiol. 1994;266:H891-7.

9. Borgdorff P, Kok WE, van den Bos GC. Extracorporeal circuits and autoregulation: effect of albumin coating. Am J Physiol. 1992;263: H1397-401.

10. Olsson P, Lagergren H, Larsson R, Radegran K. Prevention of platelet adhesion and aggregation by a glutardialdehyde-stabilized heparin surface. Thromb Haemost. 1977;37(2):274-82.

11. Mulvihill JN, Faradji A, Oberling F, Cazenave JP. Surface passivation by human albumin of plasmapheresis circuits reduces platelet accumulation and thrombus formation. Experimental and clinical studies. J Biomed Mater Res. 1990;24:155-63.

12. Savi P, Herbert JM, Pflieger AM, Dol F, Delebassee D, Combalbert J, et al. Importance of hepatic metabolism in the antiaggregating activity of the thienopyridine clopidogrel. Biochem Pharmacol. 1992;44(3):527-32.

13. Wu KK, Hoak JC. A new method for the quantitative detection of platelet aggregates in patients with arterial insufficiency. Lancet. 1974; 2(7886):924-6.

14. Savage B, Sixma JJ, Ruggeri ZM. Functional self-association of von Willebrand factor during platelet adhesion under flow. Proc Natl Acad Sci U S A. 2002;99:425-30.

15. McCrary JK, Nolasco LH, Hellums JD, Kroll MH, Turner NA, Moake JL. Direct demonstration of radiolabeled von Willebrand factor binding to platelet glycoprotein Ib and IIb-IIIa in the presence of shear stress. Ann Biomed Eng. 1995;23(6):787-93. 
16. Nesbitt WS, Kulkarni S, Giuliano S, Goncalves I, Dopheide SM, Yap $\mathrm{CL}$, et al. Distinct glycoprotein Ib/V/IX and integrin alpha(IIb)beta(3)dependent calcium signals cooperatively regulate platelet adhesion under flow. J Biol Chem. 2002;277:2965-72.

17. Goto S, Tamura N, Eto K, Ikeda Y, Handa S. Functional significance of adenosine $5^{\prime}$-diphosphate receptor $(\mathrm{P} 2 \mathrm{Y}(12))$ in platelet activation initiated by binding of von Willebrand factor to platelet GP Ibalpha induced by conditions of high shear rate. Circulation. 2002;105:2531-6.

18. Phillips DR, Charo IF, Parise LV, Fitzgerald LA. The platelet membrane glycoprotein IIb-IIIa complex [Review]. Blood. 1988;71(4):831-43.

19. Maalej N, Folts JD. Increased shear stress overcomes the antithrombotic platelet inhibitory effect of aspirin in stenosed dog coronary arteries. Circulation. 1996;93:1201-5.

20. Barstad RM, Orvim U, Hamers MJ, Tjonnfjord GE, Brosstad FR, Sakariassen KS. Reduced effect of aspirin on thrombus formation at high shear and disturbed laminar blood flow. Thromb Haemost. 1996; 75:827-32.

21. Rinder CS, Student LA, Bonan JL, Rinder HM, Smith BR. Aspirin does not inhibit adenosine diphosphate-induced platelet alpha-granule release. Blood. 1993;82:505-12.

22. Taka T, Okano E, Seki J, Yamamoto J. Effects of clopidogrel on platelet activation and coagulation of non-anticoagulated rat blood under high shear stress. Haemostasis. 1999;29:189-96.

23. Gorman MW, Ogimoto K, Savage MV, Jacobson KA, Feigl EO. Nucleotide coronary vasodilation in guinea pig hearts. Am J Physiol Heart Circ Physiol. 2003;285:H1040-7.

24. Ikeda Y, Handa M, Kawano K, Kamata T, Murata M, Araki Y, et al. The role of von Willebrand factor and fibrinogen in platelet aggregation under varying shear stress. J Clin Invest. 1991;87:1234-40.
25. Makkar RR, Eigler NL, Kaul S, Frimerman A, Nakamura M, Shah PK, et al. Effects of clopidogrel, aspirin and combined therapy in a porcine ex vivo model of high-shear induced stent thrombosis. Eur Heart J. 1998; 19:1538-46.

26. Niimi Y, Ichinose F, Ishiguro Y, Terui K, Uezono S, Morita S, et al. The effects of heparin coating of oxygenator fibers on platelet adhesion and protein adsorption. Anesth Analg. 1999;89:573-9.

27. Kuwahara M, Sugimoto M, Tsuji S, Matsui H, Mizuno T, Miyata S, et al. Platelet shape changes and adhesion under high shear flow. Arterioscler Thromb Vasc Biol. 2002;22:329-34.

28. Yu SC, Ng BT, Chan WK, Chua LP. The flow patterns within the impeller passages of a centrifugal blood pump model. Med Eng Phys. 2000;22:381-93.

29. Hongo RH, Ley J, Dick SE, Yee RR. The effect of clopidogrel in combination with aspirin when given before coronary artery bypass grafting. J Am Coll Cardiol. 2002;40:231-7.

30. Herbert JM, Dol F, Bernat A, Falotico R, Lale A, Savi P. The antiaggregating and antithrombotic activity of clopidogrel is potentiated by aspirin in several experimental models in the rabbit. Thromb Haemost. 1998;80:512-8.

31. Uthoff K, Zehr KJ, Geerling R, Herskowitz A, Cameron DE, Reitz BA. Inhibition of platelet adhesion during cardiopulmonary bypass reduces postoperative bleeding. Circulation. 1994;90:269-74.

32. Gritters M, Grooteman MP, Schoorl M, Schoorl M, Bartels PC, Scheffer $\mathrm{PG}$, et al. Citrate anticoagulation abolishes degranulation of polymorphonuclear cells and platelets and reduces oxidative stress during haemodialysis. Nephrol Dial Transplant. 2005 sep 6 [Epub ahead of print].

33. Weerwind PW, Lindhout T, Caberg NE, De Jong DS. Thrombin generation during cardiopulmonary bypass: the possible role of retransfusion of blood aspirated from the surgical field. Thromb J. 2003;1:1-9.

Access to The Journal of Thoracic and Cardiovascular Surgery Online is reserved for print subscribers!

Full-text access to The Journal of Thoracic and Cardiovascular Surgery Online is available for all print subscribers. To activate your individual online subscription, please visit The Journal of Thoracic and Cardiovascular Surgery Online, point your browser to http://www.mosby.com/jtcvs, follow the prompts to activate your online access, and follow the instructions. To activate your account, you will need your subscriber account number, which you can find on your mailing label (note: the number of digits in your subscriber account number varies from 6 to 10). See the example below in which the subscriber account number has been circled:

\section{Sample mailing label}

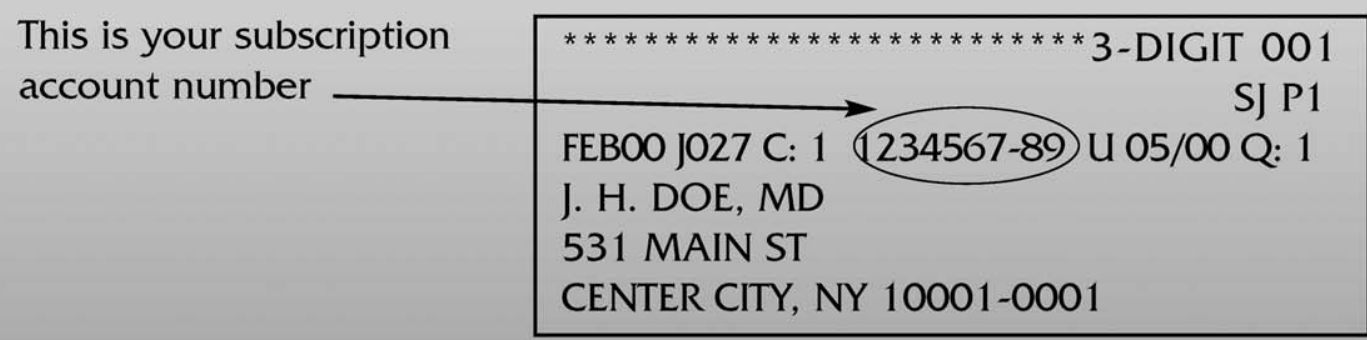

Personal subscriptions to The Journal of Thoracic and Cardiovascular Surgery Online are for individual use only and may not be transferred. Use of The Journal of Thoracic and Cardiovascular Surgery Online is subject to agreement to the terms and conditions as indicated online. 


\section{E-Appendix}

\section{Estimation of Wall Shear Stresses During}

Near-maximal Tube Compression in a Roller Pump

In a roller pump, flow is generated by repetitive forward squeezing of the peristaltic tube by a roller, as schematically shown in E Appendix Figure 1, A. Each time a roller gradually releases the tube, another roller starts the next compression. During progressive compression, the cross-sectional area in the tube under the roller becomes smaller and smaller, and flow velocity in this area increases. Under the releasing roller the reverse happens. It is to be expected that the shear stresses in the blood will be highest just before complete occlusion of the tube and shortly after reopening. At these moments the cross section of the tube takes the form of a slit (see E Appendix Figure 1, $B)$. The wall of this slit can be regarded to consist of 2 parallel flat plates. Because at small slit heights the Reynolds numbers are low, the flow in the slit approximates a laminar Poiseuille flow, and a least estimate of the fluid shear stresses at the wall of the slit can be calculated from the flow through the slit, the width and height of the slit, and blood viscosity $\left(3.6 \cdot 10^{-3} \cdot \mathrm{Pa} \cdot \mathrm{s}\right)$.

For flow between two parallel plates wall shear stress can be calculated from the Navier-Stokes equations. ${ }^{1}$ If a one-directional viscous flow is assumed, fluid shear stress $(\tau)$ is defined as the local velocity gradient multiplied by fluid viscosity $(\mu)$ :

$$
\tau=\mu \frac{d U}{d z}
$$

where $U$ is velocity, while the z-axis $(z)$ is vertically perpendicular to the flow direction (see Figure 2).

In a previous study with a static double-plate occluder, ${ }^{2}$ we have shown that, after adaptation of this equation for volume flow, the maximum shear stress at the slit wall can be calculated as:
A

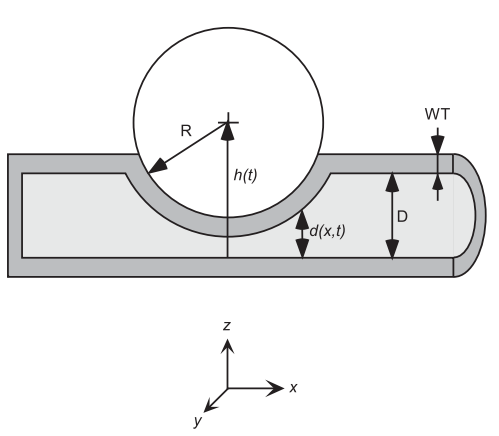

B

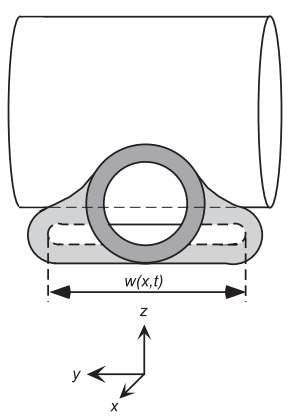

E Appendix Figure 1. Longitudinal (A) and cross-sectional view (B) of the tube compressed to a slit by one of the rollers of a pump. $x, y$, and $z$, Directions along and horizontally and vertically perpendicular to the tube centerline, respectively; $R$, roller radius; $D$, inner diameter of undeformed tube; $\boldsymbol{h}$, distance of center of roller to lower point of tube inner wall; WT, tube wall thickness; $d$, midline vertical diameter of tube during compression; $t$, time; $w$, width of slit.
E APPENDIX TABLE. Characteristics of two roller pumps used in the model for shear stress estimation

\begin{tabular}{lcc}
\hline & Small pump & Clinical pump \\
\hline Rotator radius (mm) & 15.5 & 41 \\
Rotation rate (revol/min) & 20 & 20 \\
Number of rollers & 8 & 2 \\
Roller radius (mm) & 3 & 11 \\
Tube inner diameter (mm) & 1.65 & 8.1 \\
Tube wall thickness $(\mathrm{mm})$ & 0.88 & 1.9 \\
\hline
\end{tabular}

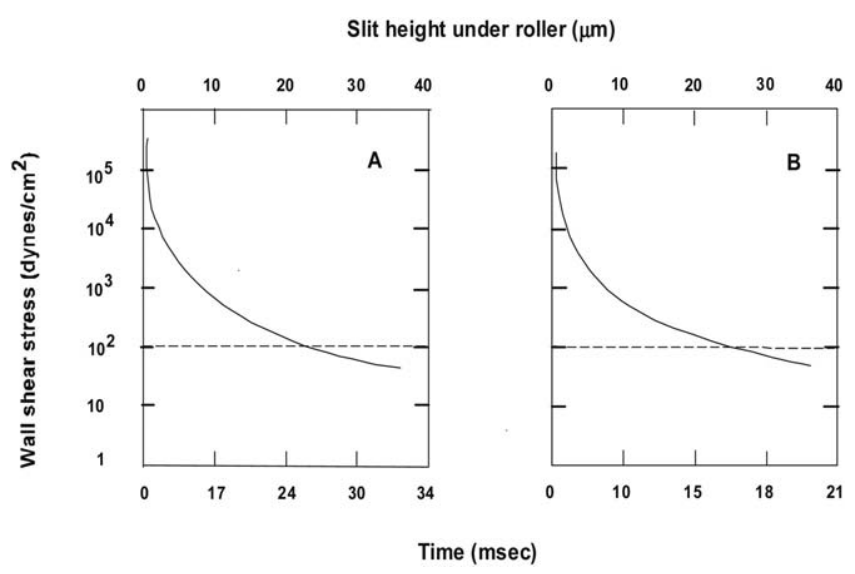

E Appendix Figure 2. Wall shear stresses in the tubing of a small pump used in a rat study (A, 8 rollers) and in an AK 10 Gambro hemodialysis pump ( $B, 2$ rollers). The lower horizontal axis depicts the time before or after complete occlusion; the upper horizontal axis indicates the slit height under a roller. The dotted line represents the level above which platelet aggregation can be expected.

$$
\tau=\mu \frac{6 Q}{w d^{2}}
$$

where $Q$ is the volume flow, $w$ the slit width, and $d$ the slit height. In a roller pump these parameters are, during near-maximal tube compression, place- and time-dependent:

$$
\tau(x, t)=\frac{6 \mu Q(x, t)}{w(x, t) d(x, t)^{2}}
$$

where $x$ is the place along the tube (see figure) and $t$ is time. The three parameters are derived as shown below.

Slit height. The height of the slit $d$ at position $x$ along the centerline (see E Appendix Figure 1, $A$ ), at time $t$ is described by

$$
d(x, t)=\min (b(x, t), D)
$$

where $b$ is the inner diameter of the tube right below the roller, and $D$ the diameter of the undeformed tube. 
$b(x, t)=h(t)-\sqrt{(\mathrm{R}+\mathrm{WT})^{2}-(x-l(t))^{2}}$ if $(x-l(t))^{2}<(\mathrm{R}+\mathrm{WT})^{2}$ Otherwise $b(x, t)=\mathrm{D}$

Here, $R$ is the radius of the roller, WT is the tube wall thickness, and $h$ and $l$ are the $z$ - and $x$-coordinates of the center of the roller as a function of time. They are given by

$$
h(t)=\mathrm{R}+\mathrm{WT}+\min \left(0, \mathrm{~V}_{\mathrm{V}} t\right) \quad \text { and } \quad l(t)=\mathrm{V}_{\mathrm{H}} t
$$

where $V_{V}$ and $V_{H}$ are the velocity of the roller in vertical and horizontal direction, respectively, as derived from the rotation rate, rotator radius, and tube inner diameter.

Slit width. It is likely that during tube deformation its inner circumference will practically remain constant (see E Appendix Figure $1, B)$. For the situation where $d$ is far smaller than $D$, the slit width at position $x$ and time $t$ can then be approximated (@) by

$$
w(x, t) \cong \frac{\pi}{2}(\mathrm{D}-d(x, t))
$$

Volume flow. We calculated $Q(x, t)$ from the maximal flow $Q_{\max }$ and its repetitive diminishment. Maximal blood flow $Q_{\max }$ through the tube occurs when the occluding roller squeezes the blood forward while none of the other rollers partially compresses the tube. The value for $Q_{\max }$ can simply be calculated by multiplying the horizontal roller velocity (ie, along the tube), with the luminal cross-sectional area of the undeformed tube:

$$
Q_{\max }=\frac{\pi}{4} \mathrm{D}^{2} \mathrm{~V}_{\mathrm{H}}
$$

Apart from the maximal flow, there is a repetitive diminishment of flow, starting when a roller other than the occluding roller begins or ends its compression. To calculate this flow diminishment, the luminal cross-sectional area of the slit at position $x$ and time $t, A(x, t)$, should be known.
Because the slit consists of three parts-a rectangle with width $w(x, t)$, complemented at both sides by two half circles with diameter $d(x, t)$ (see E Appendix Figure $1, B)-A(x, t)$ can be calculated as follows:

$$
\mathrm{A}(x, t)=\pi \cdot\left(\frac{\mathrm{D} \cdot d(x, t)}{2}-\frac{d(x, t)^{2}}{4}\right)
$$

Volume flow $Q(x, t)$ is then obtained by the difference of maximal flow and flow diminishment:

$$
Q(x, t)=Q_{\max }-\int_{x_{0}}^{x} \frac{\partial A(x, t)}{\partial t} d x
$$

where the diminishment in flow has been calculated by integrating the rate of change of cross-sectional area between any position $x_{0}$, which lies between the roller under consideration and its predecessor or successor, and position $x$.

\section{Application of the Model}

Time-varying shear stress values were estimated for a small laboratory pump used in rat experiments and for a pump used in clinical hemodialysis. The characteristics of the 2 pumps are given in E Appendix Table 1). Flow is set at 3\% to 5\% of cardiac output, that is, $3 \mathrm{~mL} / \mathrm{min}$ for the small pump and $225 \mathrm{~mL} / \mathrm{min}$ for the $\mathrm{AK}$ 10 hemodialysis pump (Gambro). The results are presented in $\mathrm{E}$ Appendix Figure 2.

\section{References}

1. Paterson AR. A first course in fluid dynamics. 4th ed. Cambridge: Cambridge University Press; 1989.

2. Borgdorff P, Kok WE, Vis MA, van den Bos GC. Vasodilation by shear-induced platelet aggregation in extracorporeal circuits. Am J Physiol 1994;266:H891-7. 